\title{
Effect of Educational Program About Partograph on Maternity Nurses' Knowledge at Qena University Hospital -Egypt
}

\author{
Reda R. Ali ${ }^{1}$, Omima M. Abd- Elzaher ${ }^{2}$, Mervat M. Hassan ${ }^{3}$, \& Shaimaa G. Hassen ${ }^{4}$. \\ ${ }^{1 .}$ Lecturer, Maternal and Newborn Health Nursing, Faculty of Nursing, Assiut University, Egypt. \\ ${ }^{2 .}$ Lecturer, Community Health Nursing, Faculty of Nursing, Sohage University, Egypt. \\ ${ }^{3 .}$ Lecturer, Obstetric and Gynecological Nursing, Faculty of Nursing, Qena University, Egypt. \\ ${ }^{4 .}$ Lecturer, Maternal and Newborn Health Nursing, Faculty of Nursing, Assiut University, Egypt.
}

\begin{abstract}
Back ground: Half a million women lose their lives every year because of pregnancy related complications. Obstructed labour and ruptured uterus contributes up to $70 \%$ of maternal mortality. Early detection of abnormal progress and prevention of prolonged labour can significantly reduce it, so Partograph is considered to be a very effective tool to monitor labour and prevent prolonged and obstructed labour. Aim: to evaluate effect of educational program about partograph on maternity nurses' knowledge at Qena University Hospital, Egypt. Subjects and Methods: A quiz -experimental research design was utilized in this study. The study was conducted at Qena University Hospital, Obstetric and Gynecological department and outpatient clinics Sample: Non probability convenience method was used as a technique of sampling; The total number of sample were consisting of 50 nurses Tools: The questionnaire was consisted of section A about demographic data section B about (questions related to partograph as fetal condition, maternal condition and progress of labour) Results: It was clear that $52.0 \%$ of nurses aged <25 years. Also mean knowledge score in pretest is $10.04 \pm 4.59$ and $40.48 \pm 3.51$ in posttest. Conclusion: The finding concluded that the educational programme was a very successful way to develop the awareness of nurses about the use of partograph. Recommendation: Application of educational program, training course and workshop for all maternity nurses to enhance their knowledge regarding how using and application of partograph.
\end{abstract}

\section{Keywords: Educational Program, Maternity Nurses \& Partograph.}

\section{Introduction}

Partogram is a Greek word meaning "Labout Curve". It comes as a page type onwhichlabout observation of labour are registered, providesa graphical summary of abour progress, and records information of maternal and foetal status during labour. Partograph is known as a very efficient instrument for measuring labour and avoiding prolonged and obstructed labour. It offers awarwness of deviations from the normal progress of labour and maternal or foetal anomalies. It provides timely data regarding further intervention as referral to higher-level facility augmentation of labour, and caesarean section. (Allauddin, et al., 2016)

Partograph was a first graphic assessment of progress of labour was designed by Friedman It is acheap instrument designed to provide a constant graphic overview of labour and has been shown to enhance outcomes when used to manage and monitor labour. The purpose of the partograph, also called the partogram, is to help midwives record, interpret, analyze, and use data to make clinical management decisions while labor is in progress. The form (which is an early warning system) provides a graphic overview of the progress of labour and records information about maternal and fetal condition during labour. (Al-Dainee, et al., 2015).

The partograph is designed for recording maternal identification, fetal heart rate, colour of the amniotic fluid, moulding of the fetal skull, cervical dilatation, fetal descent, uterine contractions, whether oxytocin was administered or intravenous fluids were given, maternal vital signs and urine output. The partograph consists of a graphic representation of labour and is an excellent visual resource to analyze cervix, uterine contraction and foetal presentation in relation to time. It is a single sheet of paper which contains information about the fetus' heart rate, any drugs used and other important elements that could assistance evade extensive descriptive notes. It also helps to facilitate duty to the person conducting labour. Procedures to monitor labor thus play a necessary role in saving life of women. (Al-Dainee, etal 2015).

The main causes of maternal deaths are hemorrhage, infection, pre-eclampsia, eclampsia, unsafe abortion, obstructed labour, anemia, hepatitis. Complications which may results as obstructed labour due to prolonged labour was commonly occur due to cephalopelvic disproportion; maternal dehydration, exhaustion, uterine rupture and vescicovaginal fistula (Dangel, 2017) 
Mathai, Switzerland, (2015) studied about the role of partograph in the prevention of prolonged labour. He pointed out that obstructed labour continues to be an important cause of maternal and perinatal mortality and morbidity. The partograph graphically appear clef events in labour and provides an early warning system. He suggested that, when used with defined management protocols, this cheap instruments can effectively monitor labour and prevent labour obstruction.

Safe motherhood article (2018) stated that the use of the partograph during labour could prevent suffering and loss of life. Thus the WHO Partograph was able to differentiate labours requiring intervention from those not requiring intervention. WHO calls for health care providers to use its partogram and its management protocol, both in labor units with the capabilities to manage and in health centers without these capabilities which can refer women who have complications in labor to a specialist place.

World Health Organization has designated management of labor with the Partograph as one of the essential components of obstetric care at the first level of referring. Although the basic idea of devising partograph was to prevent complications of prolonged labour at peripheral health care centers by providing them an easy tool to monitor the progress of labour which could even be used by the midwives and non-obstetrician doctors. (WHO, 2018)

\section{Significant of the study}

Most common causes of maternal mortality, prolonged labour and obstructed labour; they can lead to ruptured uterus, postpartum hemorrhage, infection, obstetric fistula, and fetal injury or death. Information about prolonged and obstructed labor is often non reported. The incidence of these conditions varies widely, extending from as low as $1 \%$ in some populations to as high as $20 \%$ in others; in 2000 , about 42,000 deaths, or $8 \%$ of maternal deaths, were attributed to prolonged and obstructed labor. As registration system is often poor in settings where prolonged labor, obstructed labor, and maternal deaths are more common. ( Lavender, et al., 2017 )

There are little studies regarding Effect of Educational Program About Pantograph on Maternity Nurses' Knowledge at Qena University Hospital Egypt So the present study had been conducted at this area because there is no enough information about use of Partograph among nurses at Qena Hospital and in centers of qena .

Aims of the study

1. Assessing maternity nurses' knowledge regarding partograph.
2. Evaluating effect of educational program about partograph on maternity nurses' knowledge at Qena University Hospital.

Research hypothesis

Nurses who attened educational programme about partograph exihibit more knowledge than before attending program.

Subjects \& Methods

Technical design

Research design

A quiz -experimental research design was utilized in this study.

Study Setting

The study was conducted.in Obstetric and Gynecological department and outpatient clinics at Qena University Hospital - Egypt.

Sample

The sampling technique use in this study was non probability convenience method of sampling (total coverage) for maternity nurses. The total number of all maternity nurses (50 nurses) working at Obstetric and Gynecological department and outpatient clinics.

\section{Study tools}

A structured self-administered sheet was designed by the researchers based on relevant literature in order to reached aims of the study. It was consisted of (2) sections:

Section A: - Self-administered questionnaire sheet related to (demographic data of the nurses). This part is concerned with the collection of basic sociodemographic data, this part is filled by the nurses (age, level of education, duration of nursing experiences at the maternity unit, number and duration of participation in partograph training sessions in the hospital).

Section B: includes five parts Self-administered questionnaire sheet related to (nurses' knowledge regarding Partograph. It was constructed to assess nurse's knowledge about partograph in maternity units and labor rooms. The questionnaire sheet is also filled by the nurses, after purpose of the study is explained to get questionnaire sheet. The participants are requested to answer the questionnaire within 30 minutes.

First part: -Questions related to knowledge of nurses about normal labour such as number of stages of labour, First stages of labor, the Initial (Latent) Phase start, average length of initial (Latent) phase)

Second part: - Questions related to Partograph such as what is a partograph, in which stage of labour is the partograph used, most important use of partograph, and components of the partograph.

Third part: - Specific Questions related to fetal and liquor condition such as (normal range of FHR, 
causes of abnormal FHR, letter is used to record on partograph, when the membranes are intact, color of meconium stained amniotic fluid)

Fourth part: Specific Questions related to progress of labour such as (what are the two special lines present in partogram, what is indicated when the Cervicograph crosses the action line, how much is the full cervical dilatation, what are the degrees of uterine contractions?)

Fifth part: Specific Questions related to Maternal condition such as (how frequently is the BP checked \& recorded in partograph?, how frequently is the pulse rate checked and recorded in partograph?, how frequently is the temperature checked and recorded in partograph?)

Scoring system for knowledge as follow

Scoring system designed for the assessment of knowledge, a score of 1 grade was given for each correct answer and a score of zero grade was given for each incorrect answers. The score of each item summed-up and then mean of summation is calculated.

\section{Validity of study tools}

Content validity of the study tool was reviewed by jury group that involved three experts in maternity and newborn health nursing and two experts of community health nursing for comprehensiveness, accuracy and clarity of language. Who recommended face and content validity of all items. All recommended modifications were performed and the tool was tested through the pilot study.

\section{Reliability test}

Reliability was applied by the researchers for testing the internal of the tool, by administration of the same tools to the same subjects. Estimated by using Cronbach's Alpha; and it was 0.791

\section{Operational design}

\section{Pilot Study}

A pilot study was carried out before starting data collection on (10\%) (5 of nurses), were included from the total number of study sample. The aim of pilot study was to test the clarity of tools, and to estimate the time required to fill the form. According to the result of the pilot study necessary modification was done.

Field of work: Data were collected and educational program started from the first of December 2018 until the end of may 2019 about 6 months consumed.

After explaining the purpose of the study and obtaining her consent to participate in the study with confidentiality. The researchers couldn't divide the nurses to groups to prevent work interruption during filling sheet (pre-test). The average time taken to complete each sheet ranged from 20- 30 minutes.
Then after filling questionnaire from nurses the researchers divided nurses to groups to attend sessions every session includes 3-5 nurses according to work in units to avoid work interruption. Educational program about knowledge was explained to them and how to use partograph in form of power point presentation and this lecture took about 2 hours, covering most important points about partograph and giving nurses examples about using partograph. The educational program that designed in form of power point presentation provide the nurses with information about partograph, Fetal condition as (membranes, liquor, and fetal head molding), progress of labor as (uterine Contraction, cervical dilation, decent of fetal head, and Alert and Action lines of partograph), maternal condition, as (temperature, pulse, blood pressure, and urine character). Then nurses' knowledge was assessed again after 2 weeks from educational program (posttest) to give nurses chance to interpret and solute examples about partograph.

\section{Administrative phase}

An approval letter was taken from the Dean of the Faculty of Nursing, Qena University and then from the Directorate of Qena University Hospital to conduct the study. After full explanation about the aim of the study. The letter included a permission to carry out the study.

\section{Ethical consideration}

To achieve this study, necessary approval was obtained from the responsible authorities of Qena University Hospital. Informed consent was obtained from every nurse participate in the study after explaining the aim and nature of the study. Also, confidentiality was maintained during the research process.

\section{Statistical design}

Data entry and analysis were done using SPSS version 18 Program statistical software package for social sciences. Data were presented using descriptive statistics in the form of frequencies and percentages. Also, Mean was calculated. Correlation between variables (Mc Nemar test for pair qualitative variables and chi square) used were used statistical significance difference was considered at $\mathrm{P}$-value $\leq 0.05$ and highly statistical significance was considered at $\mathrm{P}$-value $\leq 0.01$. 


\section{Results}

Table (1): Distribution of studied nurses regarding sociodemographic characteristics:

\begin{tabular}{|l|c|c|}
\hline \multicolumn{1}{|c|}{ Item } & No. (50) & \% \\
\hline Age: (years) & & 52.0 \\
\hline$<25$ & 26 & 48.0 \\
\hline$\geq 25$ & \multicolumn{2}{|c|}{$24.92 \pm 4.65(19.0-35.0)$} \\
\hline Mean \pm SD (Range) & \multicolumn{2}{|c|}{} \\
\hline Years of experience: & 33 & 66.0 \\
\hline$\leq 5$ & 17 & 34.0 \\
\hline$>5$ & \multicolumn{2}{|c|}{$4.91 \pm 3.44(4 \mathrm{~m}-14 \mathrm{y})$} \\
\hline Mean \pm SD (Range) & \multicolumn{2}{|c|}{} \\
\hline $\begin{array}{l}\text { Participation in training sessions about } \\
\text { partograph: }\end{array}$ & 0 & 0.0 \\
\hline Yes & 50 & 100.0 \\
\hline No & $\mathbf{5 0}$ & $\mathbf{1 0 0 . 0}$ \\
\hline Total & & \multicolumn{2}{|c|}{} \\
\hline
\end{tabular}

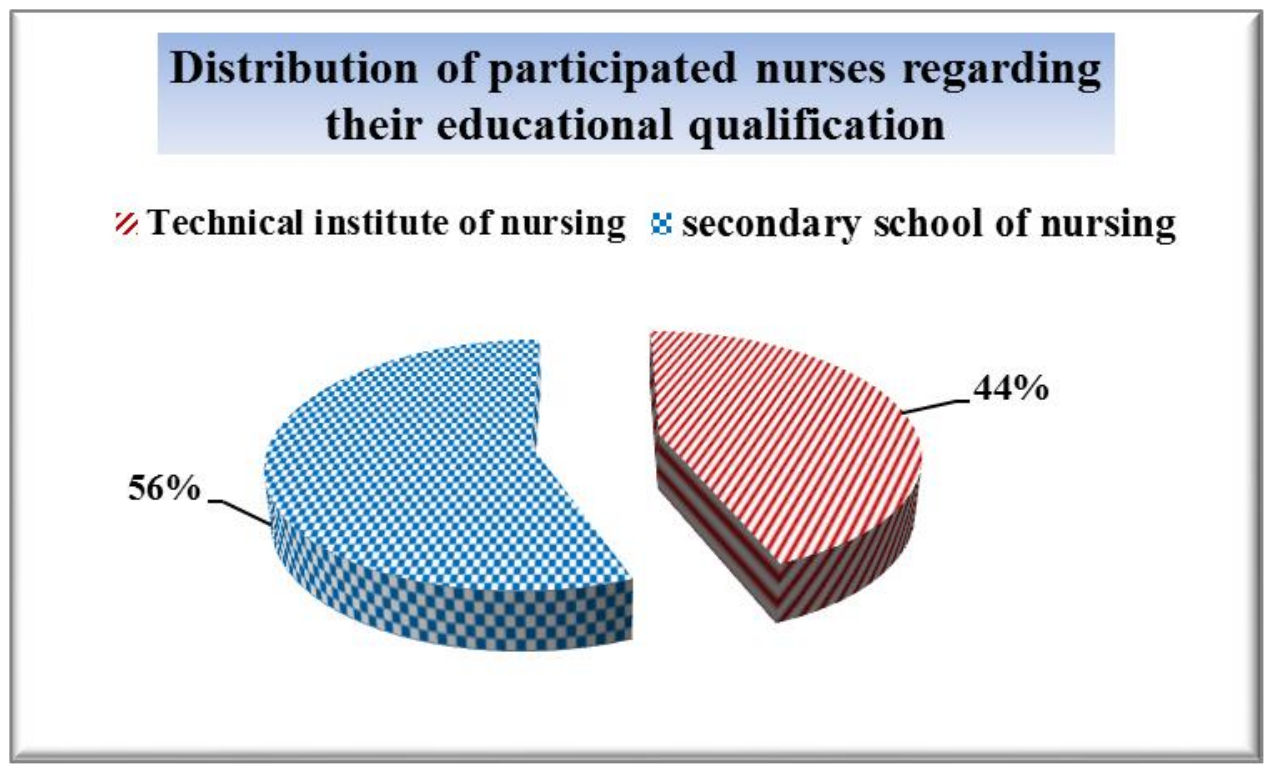

Figure (1) Distribution of participated nurses regarding their educational qualification:

Table (2): Distribution of studied nurses regarding knowledge about normal labour $\mathbf{n}=(50$ nurse $)$

\begin{tabular}{|c|c|c|c|c|c|c|c|c|c|}
\hline \multirow{3}{*}{ Item } & \multicolumn{4}{|c|}{$\begin{array}{c}\text { Pre-test } \\
(n=50)\end{array}$} & \multicolumn{4}{|c|}{$\begin{array}{c}\text { Post-test } \\
(n=50)\end{array}$} & \multirow{3}{*}{ P-value } \\
\hline & \multicolumn{2}{|c|}{ Correct } & \multicolumn{2}{|c|}{ Incorrect } & \multicolumn{2}{|c|}{ Correct } & \multicolumn{2}{|c|}{ Incorrect } & \\
\hline & No. & $\%$ & No. & $\%$ & No. & $\%$ & No. & $\%$ & \\
\hline No. of labour stages & 6 & 12.0 & 44 & 88.0 & 50 & 100.0 & 0 & 0.0 & 0.000 \\
\hline Time of starting first stage of labour & 6 & 12.0 & 44 & 88.0 & 44 & 88.0 & 6 & 12.0 & $0.000^{\circ-}$ \\
\hline $\begin{array}{l}\text { When dose the Initial (Latent) Phase } \\
\text { start }\end{array}$ & 9 & 18.0 & 41 & 82.0 & 44 & 88.0 & 6 & 12.0 & $0.000^{* *}$ \\
\hline $\begin{array}{l}\text { Average length of Initial (Latent) } \\
\text { phase }\end{array}$ & 10 & 20.0 & 40 & 80.0 & 45 & 90.0 & 5 & 10.0 & $0.000^{* *}$ \\
\hline $\begin{array}{l}\text { Time of starting active phase of } \\
\text { labour }\end{array}$ & 36 & 72.0 & 14 & 28.0 & 47 & 94.0 & 3 & 6.0 & $0.003^{* *}$ \\
\hline $\begin{array}{l}\text { Average length of active phase in } \\
\text { labour }\end{array}$ & 3 & 6.0 & 47 & 94.0 & 47 & 94.0 & 3 & 6.0 & $0.000^{* *}$ \\
\hline
\end{tabular}

$p$ value $0.000 * *$ highly significant 
Table (3): Distribution of studied nurses regarding Knowledge about definition of partograph: $\mathbf{n}=(50 \mathrm{nurse})$

\begin{tabular}{|c|c|c|c|c|c|c|c|c|c|}
\hline \multirow{3}{*}{ Item } & \multicolumn{4}{|c|}{$\begin{array}{l}\text { Pre-test } \\
(n=50)\end{array}$} & \multicolumn{4}{|c|}{$\begin{array}{c}\text { Post-test } \\
(n=50)\end{array}$} & \multirow{3}{*}{ P-value } \\
\hline & \multicolumn{2}{|c|}{ Correct } & \multicolumn{2}{|c|}{ Incorrect } & \multicolumn{2}{|c|}{ Correct } & \multicolumn{2}{|c|}{ Incorrect } & \\
\hline & No. & $\%$ & No. & $\%$ & No. & $\%$ & No. & $\%$ & \\
\hline $\begin{array}{l}\text { Who was the first to develop the } \\
\text { idea of recording the progress of } \\
\text { labour on a chart? }\end{array}$ & 7 & 14.0 & 43 & 86.0 & 49 & 98.0 & 1 & 2.0 & $0.000^{* *}$ \\
\hline What is a partograph? & 2 & 4.0 & 48 & 96.0 & 39 & 78.0 & 11 & 22.0 & $0.000^{* * *}$ \\
\hline $\begin{array}{l}\text { In which stage of labour is the } \\
\text { partograph used? }\end{array}$ & 32 & 64.0 & 18 & 36.0 & 50 & 100.0 & 0 & 0.0 & $0.000^{* *}$ \\
\hline $\begin{array}{l}\text { The most important use of } \\
\text { Partogram? }\end{array}$ & 7 & 14.0 & 43 & 86.0 & 47 & 94.0 & 3 & 6.0 & $0.000^{* *}$ \\
\hline $\begin{array}{l}\text { Basic components of the } \\
\text { partogram }\end{array}$ & 9 & 18.0 & 41 & 82.0 & 42 & 84.0 & 8 & 16.0 & $0.000^{* *}$ \\
\hline
\end{tabular}

p value $0.000^{* * \text { highly significant }}$

Table (4): Distribution of studied nurses regarding knowledge about fetal condition: $n=(50$ nurse $)$

\begin{tabular}{|c|c|c|c|c|c|c|c|c|c|}
\hline \multirow{3}{*}{ Item } & \multicolumn{4}{|c|}{$\begin{array}{l}\text { Pre-test } \\
(n=50)\end{array}$} & \multicolumn{4}{|c|}{$\begin{array}{l}\text { Post-test } \\
(n=50)\end{array}$} & \multirow{3}{*}{ P-value } \\
\hline & \multicolumn{2}{|c|}{ Correct } & \multicolumn{2}{|c|}{ Incorrect } & \multicolumn{2}{|c|}{ Correct } & \multicolumn{2}{|c|}{ Incorrect } & \\
\hline & No. & $\%$ & No. & $\%$ & No. & $\%$ & No. & $\%$ & \\
\hline $\begin{array}{l}\text { What the items evaluate fetal } \\
\text { condition on partograph }\end{array}$ & 12 & 24.0 & 38 & 76.0 & 47 & 94.0 & 3 & 6.0 & $0.000^{* * *}$ \\
\hline Normal range of FHR & 6 & 12.0 & 44 & 88.0 & 49 & 98.0 & 1 & 2.0 & $0.000^{* *}$ \\
\hline Causes of abnormal FHR & 8 & 16.0 & 42 & 84.0 & 47 & 94.0 & 3 & 6.0 & $0.000^{* *}$ \\
\hline $\begin{array}{l}\text { If moulding is present its } \\
\text { marked as }\end{array}$ & 19 & 38.0 & 31 & 62.0 & 50 & 100.0 & 0 & 0.0 & $0.000^{* * *}$ \\
\hline $\begin{array}{l}\text { What does severe moulding } \\
\text { indicate }\end{array}$ & 6 & 12.0 & 44 & 88.0 & 41 & 82.0 & 9 & 18.0 & $0.000^{* * *}$ \\
\hline $\begin{array}{l}\text { Which letter is used to record on } \\
\text { partograph when the } \\
\text { membranes are intact? }\end{array}$ & 20 & 40.0 & 30 & 60.0 & 50 & 100.0 & 0 & 0.0 & $0.000^{* * *}$ \\
\hline $\begin{array}{l}\text { Which letter is used to record on } \\
\text { partograph when the } \\
\text { membranes are rupture? }\end{array}$ & 15 & 30.0 & 35 & 70.0 & 50 & 100.0 & 0 & 0.0 & $0.000^{* * *}$ \\
\hline $\begin{array}{l}\text { What is the colour of meconium } \\
\text { stained amniotic fluid? }\end{array}$ & 11 & 22.0 & 39 & 78.0 & 40 & 80.0 & 10 & 20.0 & $0.000^{\text {*** }}$ \\
\hline $\begin{array}{l}\text { Which of the following fresh } \\
\text { bright red blood in amniotic } \\
\text { fluid? }\end{array}$ & 8 & 16.0 & 42 & 84.0 & 40 & 80.0 & 10 & 20.0 & $0.000^{\text {*** }}$ \\
\hline $\begin{array}{l}\text { Dark green meconium of } \\
\text { amniotic fluid means }\end{array}$ & 5 & 10.0 & 45 & 90.0 & 42 & 84.0 & 8 & 16.0 & $0.000^{* * *}$ \\
\hline $\begin{array}{l}\text { What does the markings 'b' } \\
\text { 'indicate with regard to amniotic } \\
\text { fluid? }\end{array}$ & 12 & 24.0 & 38 & 76.0 & 44 & 88.0 & 6 & 12.0 & $0.000^{* * *}$ \\
\hline
\end{tabular}

p value $0.000^{* * \text { highly significant }}$ 
Table (5): Distribution of studied nurses regarding knowledge about progress of labour: $n=(50$ nurse $)$

\begin{tabular}{|c|c|c|c|c|c|c|c|c|c|}
\hline \multirow{3}{*}{ Item } & \multicolumn{4}{|c|}{$\begin{array}{c}\text { Pre-test } \\
(n=50)\end{array}$} & \multicolumn{4}{|c|}{$\begin{array}{c}\text { Post-test } \\
(n=50)\end{array}$} & \multirow{3}{*}{ P-value } \\
\hline & \multicolumn{2}{|c|}{ Correct } & \multicolumn{2}{|c|}{ Incorrect } & \multicolumn{2}{|c|}{ Correct } & \multicolumn{2}{|c|}{ Incorrect } & \\
\hline & No. & $\%$ & No. & $\%$ & No. & $\%$ & No. & $\%$ & \\
\hline $\begin{array}{l}\text { What are the two special lines present in } \\
\text { partogram? }\end{array}$ & 8 & 16.0 & 42 & 84.0 & 48 & 96.0 & 2 & 4.0 & $0.000^{* * *}$ \\
\hline $\begin{array}{l}\text { What is indicated when the Cervicograph } \\
\text { crosses the Action line? }\end{array}$ & 1 & 2.0 & 49 & 98.0 & 43 & 86.0 & 7 & 14.0 & $0.000^{* *}$ \\
\hline How much is the full cervical dilatation? & 16 & 32.0 & 34 & 68.0 & 50 & 100.0 & 0 & 0.0 & $0.000^{* *}$ \\
\hline What do you mean by cervical effacement? & 5 & 10.0 & 45 & 90.0 & 34 & 68.0 & 16 & 32.0 & $0.000^{* *}$ \\
\hline $\begin{array}{l}\text { What does the term "frequency" denote } \\
\text { with regard to uterine contraction? }\end{array}$ & 5 & 10.0 & 45 & 90.0 & 42 & 84.0 & 8 & 16.0 & $00^{* *}$ \\
\hline $\begin{array}{l}\text { What are the degrees of } \\
\text { contractions? }\end{array}$ & 3 & 6.0 & 47 & 94.0 & 38 & 76.0 & 12 & 24.0 & $0.000^{* *}$ \\
\hline $\begin{array}{l}\text { What is the nature of the fundus during } \\
\text { strong contractions? }\end{array}$ & 6 & 12.0 & 44 & 88.0 & 50 & 100.0 & 0 & 0.0 & $0.000^{* *}$ \\
\hline $\begin{array}{l}\text { What is the duration of weaker } \\
\text { contractions? }\end{array}$ & 11 & 22.0 & 39 & 78.0 & 47 & 94.0 & 3 & 6.0 & $0.000^{* *}$ \\
\hline $\begin{array}{l}\text { What is the duration of moderate } \\
\text { contractions? }\end{array}$ & 7 & 14.0 & 43 & 86.0 & 41 & 82.0 & 9 & 18.0 & $0.000^{* *}$ \\
\hline $\begin{array}{l}\text { What is the duration of stronger } \\
\text { contractions? }\end{array}$ & 10 & 20.0 & 40 & 80.0 & 33 & 66.0 & 17 & 34.0 & $0.000^{* *}$ \\
\hline How are the uterine contractions measured? & 11 & 22.0 & 39 & 78.0 & 48 & 96.0 & 2 & 4.0 & $0.000^{* *}$ \\
\hline $\begin{array}{l}\text { How often can we perform the vaginal } \\
\text { examination? }\end{array}$ & 4 & 8.0 & 46 & 92.0 & 38 & 76.0 & 12 & 24.0 & $0.000^{* *}$ \\
\hline How to record cervical dilatation marked by & 33 & 66.0 & 17 & 34.0 & 50 & 100.0 & 0 & 0.0 & $0.000^{* * *}$ \\
\hline How to record fetal head descent marked by & 27 & 54.0 & 23 & 46.0 & 50 & 100.0 & 0 & 0.0 & $0.000^{* * *}$ \\
\hline How to identify the descent of fetal head? & 7 & 14.0 & 43 & 86.0 & 27 & 54.0 & 23 & 46.0 & $0.000^{* * *}$ \\
\hline $\begin{array}{l}\text { Descent of fetal head corresponding marked } \\
\text { on the partograph }\end{array}$ & 5 & 10.0 & 45 & 90.0 & 44 & 88.0 & 6 & 12.0 & $0.000^{* *}$ \\
\hline
\end{tabular}

p value $0.000^{* *}$ highly significant

Table (6): Distribution of studied nurses regarding knowledge about maternal condition: $n=(50$ nurse $)$

\begin{tabular}{|c|c|c|c|c|c|c|c|c|c|}
\hline \multirow{3}{*}{ Item } & \multicolumn{4}{|c|}{$\begin{array}{c}\begin{array}{c}\text { Pre-test } \\
(\mathbf{n}=50)\end{array} \\
\end{array}$} & \multicolumn{4}{|c|}{$\begin{array}{c}\text { Post-test } \\
(\mathrm{n}=50)\end{array}$} & \multirow{3}{*}{ P-value } \\
\hline & \multicolumn{2}{|c|}{ Correct } & \multicolumn{2}{|c|}{ Incorrect } & \multicolumn{2}{|c|}{ Correct } & \multicolumn{2}{|c|}{ Incorrect } & \\
\hline & No. & $\%$ & No. & $\%$ & \begin{tabular}{|l|} 
No. \\
\end{tabular} & $\%$ & No. & $\%$ & \\
\hline $\begin{array}{l}\text { How frequently is the BP checked \& recorded in } \\
\text { partograph? }\end{array}$ & 1 & 2.0 & 49 & 98.0 & 42 & 84.0 & 8 & 16.0 & $0.000^{* * *}$ \\
\hline $\begin{array}{l}\text { How frequently is the pulse rate checked and } \\
\text { recorded in partograph? }\end{array}$ & 5 & 10.0 & 45 & 90.0 & \begin{tabular}{|l|}
48 \\
\end{tabular} & 96.0 & 2 & 4.0 & $0.000^{* * *}$ \\
\hline $\begin{array}{l}\text { How frequently is the temperature checked and } \\
\text { recorded in partograph? }\end{array}$ & 21 & 42.0 & 29 & 58.0 & \begin{tabular}{|l|}
46 \\
\end{tabular} & 92.0 & 4 & 8.0 & 0.000 \\
\hline $\begin{array}{l}\text { How much rise in Blood pressure during labour } \\
\text { is considered as normal? }\end{array}$ & 9 & 18.0 & 41 & 82.0 & 49 & 98.0 & 1 & 2.0 & $0.000^{* * *}$ \\
\hline What does pyrexia during labour indicate? & 6 & 12.0 & 44 & 88.0 & 43 & 86.0 & 7 & 14.0 & $0.000^{* * *}$ \\
\hline What does proteinuria indicate? & 38 & 76.0 & 12 & 24.0 & 48 & 96.0 & 2 & 4.0 & $0.004^{* * *}$ \\
\hline
\end{tabular}

p value $0.000 * *$ highly significant 


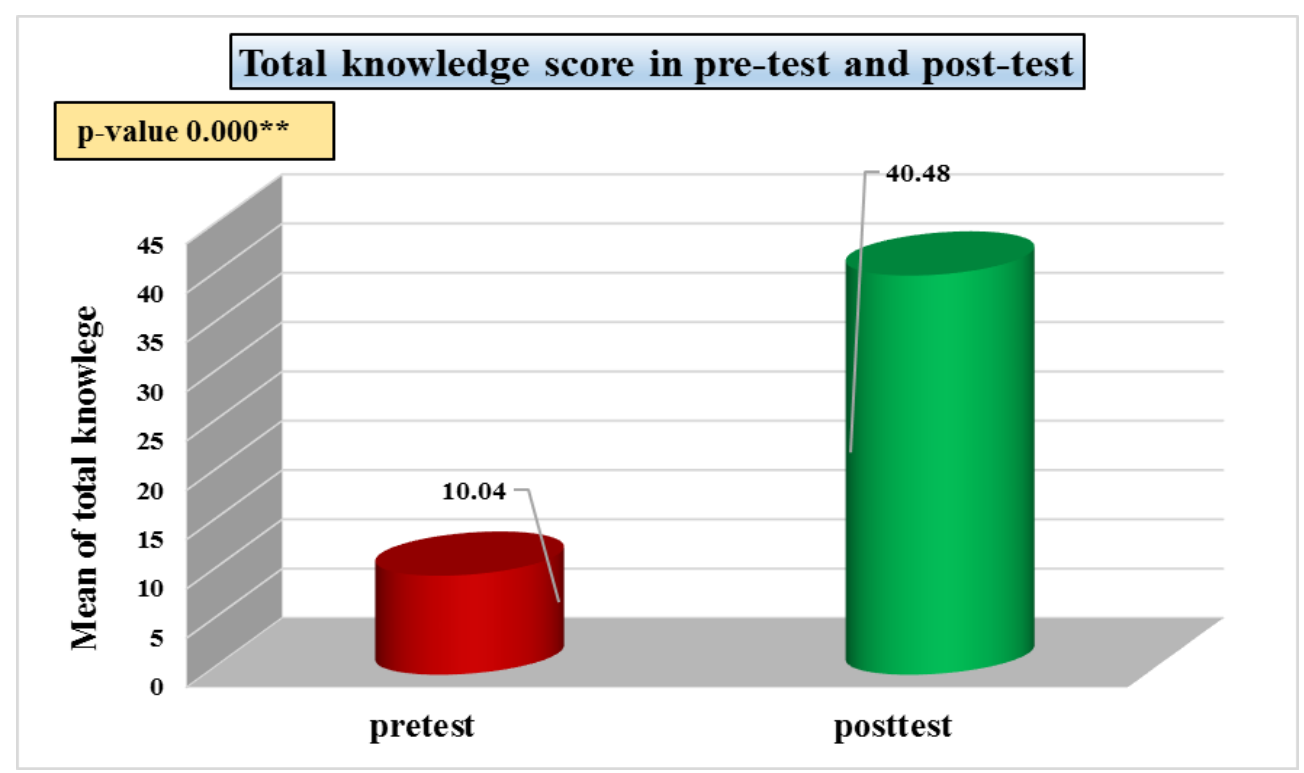

Figure (2): Total knowledge score in pre-test and post-test

Table (7): Relation between score of knowledge and socio-demographic data:

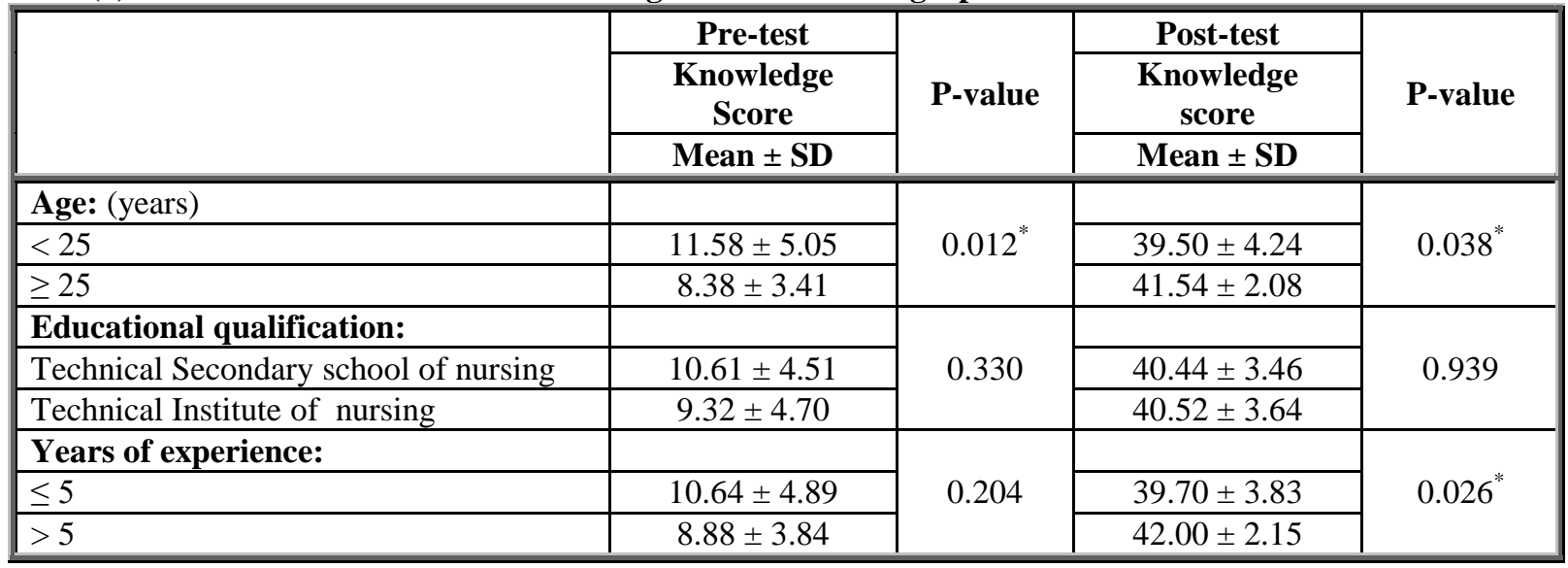

p value $0.000 * *$ highly significant

Table (1): Illustrates distribution of participated nurses regarding their personnel characteristics. It is showed that $52.0 \%$ of them their age is less than 25 years old, with a mean age of $(24.92 \pm 4.65(19.0-$ 35.0). In addition, $66.0 \%$ of nurses have a Years of experience of less than 5 years and all of them haven't any training sessions about partograph.

Figure (1): Shows distribution of participated nurses regarding their educational qualification, and reports that $56.0 \%$ of nurses have a secondary school of nursing.

Table (2): Show that there was a highly statistical significant difference between their general knowledge regarding normal labour pre and post intervention ( $\mathrm{p}$ value $0.000 *$ )
As shown in table (3): There was a highly statistical significant difference between maternity nurses' knowledge regarding general questions related to partograph in pre and post intervention ( $\mathrm{p}$ value $0.000^{*}$ )

As shown in table (4): There was a highly statistical significant difference between maternity nurses' knowledge regarding specific questions (Fetal and liquor condition) related partograph in pre and post intervention ( $\mathrm{p}$ value $0.000^{*}$ ).

As shown in table (5): There was a highly statistical significant difference between maternity nurses' knowledge regarding specific questions (progress of labour) related partograph in pre and post intervention ( $\mathrm{p}$ value $0.000^{*}$ ). 
As shown in table (6): There is a highly statistical significant difference between maternity nurses' knowledge regarding specific questions (maternal) related partograph in pre and post intervention ( $p$ value $0.000^{*}$ and $0.004^{*)}$.

Figure (2): Indicates that, there was a highly statistical significant difference between their total knowledge score pre and post intervention $(\mathrm{p}<0.000)$.

Table (7): Demonstrates that, there is a highly statistical significant difference between total knowledge score and nurses' age in pre and post intervention $\mathrm{p}$-value $\left(0.012^{*}\right.$ and $\left.0.038^{*}\right)$. For, and no statistical significant difference between total knowledge score and nurses' educational qualification in pre and post intervention $\mathrm{p}$-value (0.330 and 0.939$)$. and regarding years of experience p-value is $\left(0.204 .0 .026^{*}\right)$ in pre and post intervention respectively.

\section{Discussion}

WHO recommends using its modified partograph to monitor every woman during intrapartum period (Pokhrel et al., 2018) to enhance health care and reduce maternal and fetal morbidity and mortality (Yisma et al., 2013) So this study aims to evaluate the effect of teaching guidelines regarding partograph on nurses' knowledge.

Pre and posttest provide a basic mean to the learner theoretical knowledge and give a chance to improve level of knowlege (Macones et al., 2019)

Regarding total knowledge about partograph in pre and posttest the present study reveales that there is a mean knowledge of $10.04 \pm 4.59$ in pretest and $40.48 \pm 3.15$ in posttest with statistical significant difference between pre and posttest p-value is 0.000 .

This was on the same line with (Abhari F et al., 2014), who applied their study in Iran to assess effect of teaching program on knowledge about partogram among fourth year B.Sc nursing students, and found that the mean of total knowledge in pretest was 9.44 2.02 and in posttest was $42.1 \pm 2.12$, with statistical significant difference between pre and posttest.

Also (Pokhrel et al., 2018), who performed their study in Samdrup Jongkhar District, Bhutan to identify knowledge, interpretation and documentation status of partograph, and reported that there was statistical significant difference between pre and posttest regarding the mean of total knowledge pvalue was 0.000 .

The same opinion was to (Jumaah \& Nasir, 2016), who carried out their study at Al-Najaf City to assess the effect of educational program on nurses' knowledge about partograph, and illustrated that the total knowledge regarding partograph was poor in pretest and good in posttest, with statistical significant difference between pre and posttest pvalue was 0.001 .

On the other hand, (Nattah et al., 2019), who implemented their study in Al-Hilla Hospitals to evaluate the effect of teaching program on midwives' knowledge regarding use of partograph during first stage of labor, and showed that the mean of total knowledge in pretest was 3.96 1.99 and in posttest was $9.56 \pm 0.77$, with statistical significant difference between pre and posttest. This difference back to only around one quarter of midwives had previous using of the partograph.

According to general knowledge about partograph, the actual study reports that less than one quarter in pretest and the majority of studied nurses in posttest know the meaning of partograph, its importance and basic component of the partograph. With statistical significant difference between pre and posttest pvalue is 0.000 for all.

This was nearly agreed with (Nattah et al., 2019), who clarified that around one third of midwives in pretest and the majority of them in posttest know the meaning of partograph, purpose of it and its basic component. With statistical significant difference between pre and posttest p-value was 0.001 .

But (Al-dainee, 2015) disagreed with previous words, who performed their study in Karbala City Hospital to assess effect of teaching program about partograph on midwives' knowledge, and showed that less than one half in pretest and all of midwives in posttest know the meaning of partograph. the majority of them in pretest and the great majority of midwives in posttest know the purpose and component of the partograph. With statistical significant difference between pre and posttest. This dis agreement especially in pretest back to the majority of midwives in this study had previous experience on using partograph.

As regard labor progress part of the partograph, the current study demonstrates that more than one sixth of studied nurses in pretest and the majority of them in posttest know the correct answer regarding special lines present on the partograph, duration of weaker and stronger contraction. With statistical significant difference between pre and posttest p-value was 0.000 .

This was supported by (Okusanya et al., 2018) who applied their study in Nigeria to assess the effect of training on the knowledge and use of the partograph among health workers, and clarified that there was statistical significant difference between pre and post training regarding knowledge about labor progress part of the paratograph (cervical dilatation and uterine contraction) p-value was 0.001 . 
The same opinion was to (Al-dainee, 2015) who revealed that there was statistical significant difference between pre and post training regarding knowledge about labor progress part of the paratograph p-value was 0.001 .

But, (Agan et al., 2014) who performed their study in Nigeria to assess knowledge and utilization of the partograph among maternity care givers, and found that more than one half of participants know the correct answer to some questions regarding labor progress part of the paratograph. This difference in percent without training back to the majority of obstetrics care providers had less than 5 years' experience in their work.

Concerning knowledge about fetal condition part of the paratograph, the current study clarifies that there is statistical significant difference between pre and post regarding normal FHR, marking of moulding, intact and rupture membrane and color of meconium stained amniotic fluid, p-value are 0.000 for all.

This was the same line of (Manohari, 2010) who carried out their study in selected maternity hospitals at Erode to evaluate effect of self-instructional module on partograph in terms of knowledge among the maternity nurses' staff, and reported that there was statistical significant difference between pre and post regarding knowledge about specific fetal condition of the paratograph.

Also (Al-dainee, 2015) presented that there was statistical significant difference between pre and post regarding knowledge about fetal parameters of the paratograph, p-value was 0.001 . This agreement back to working on the same sample type (maternity health care providers or nurses).

Regarding knowledge about maternal conditions part of the paratograph, the present study shows that there is statistical significant difference between pre and posttest, p-value is 0.000 .

This was the same opinion of (Manohari, 2010) who stated that there was statistical significant difference between pre and post regarding maternal components of the paratograph.

When referring to relation between total knowledge about partograph and personal data, the current study represents that there is relation between nurses' age and total knowledge in pre and posttest, p-value is 0.012 and 0.038 . But there is no relation between educational qualifications and total knowledge about partograph in pre and posttest, p-value is 0.330 and 0.939. While there is no relation between years of experience and total knowledge about partograph in pretest p-value is 0.204 , but there is relation between them in postest $\mathrm{p}$-value is 0.026 .

(Agan et al., 2014) agreed with previous opinion, who illustrated that there was relation between nurses' age and total knowledge about partograph, pvalue is 0.016 , and there was no relation between years of experience and total knowledge about partograph p-value is 0.220 .

On the other side, (Kaur, 2019) who performed their study in India to assess knowledge about partograph among staff nurses, and showed that there was no relation between nurses' age and total knowledge about partograph, p-value is 0.265 .

According to personal data, the present study shows that more than one half of studied nurses have age less than 25 years, with a mean age of $24.92 \pm 4.65$, have a secondary school of nursing education and have an experience of 5 years or less.

This was on the same line with (Pokhrel et al., 2018) who reported that around one half of participants had an age group less than 29 years with a mean of $30 \pm 7.13$, had a diploma educational level and had a 5 years or less of experience in the work.

But, (Manohari, 2010) clarified that less than one half of nursing staff had an age less than 25 years, had a secondary nursing school and had an experience in their work of less than 5 years.

\section{Conclusion}

Based on the results of the present study, it can be concluded that:

It concluded that the studied nurses had poor score knowledge regarding partograph use in pretest. indicates that, there was a highly statistical significant difference between their total knowledge score pre and post intervention $(\mathrm{p}<0.000 *)$.

It concluded that, there was a highly statistical significant difference between their total knowledge score and personal data pre and post intervention $(0.012 *$ and $0.038 *)$. For age, (0.330 and 0.939) about Educational qualification (Secondary school of nursing and Institute in nursing) and (0.204. 0.026*) Years of experience. The finding concluded that the intervention was very effective in increasing their knowledge regarding using of partograph.

\section{Recommendations}

Based on the study results discussion and conclusions the study recommended that:

1. Asserting on Ministry of Health to offer in service training programs for nurses and midwife, also encouraging nurses to be enrolled in educational sessions and programs to improve their knowledge and keep their knowledge up to date about partograph.

2. Enhance the nurse's knowledge regarding partograph by frequent teaching program, training course and workshops for all nurses especially in delivery room. 3- Multimedia 
advertising for using partograph especially in the maternity units.

3. Suggestion for further studies which will be conducted in large population to explore the gap between knowledge, of nurses regarding partograph.

4. Developing of follow up system in maternity units to evaluate the performance of nurses who had previously attended the partograph teaching program and encourage peer monitoring for nurses.

5. Emphasize on the importance of using partograph in delivery rooms.

6. Application of educational program, training course and workshop for all maternity nurses in a wide region for all centers of maternity and child units in qena city to enhance their knowledge regarding how use and application of partograph.

Acknowledgments: The authors would like to convey special thanks to all nurses included in the study and to all individuals shared in the data collection.

\section{References}

- Abhari F., Andarieh M., Ledari F., \& \& Ahmady S., (2014): A Study to assess the Effectiveness of Planned Teaching Program on Knowledge Regarding Partogram Among Fourth Year B.Sc Nursing Students of Karnataka College of Nursing at Bangalore. Bulletin of Environment, Pharmacology and Life Sciences, 3(5), 24-36.

- Agan, T., Akpan, U., Okokon, I., Oku, A., Asibong, U., Opiah, M., Essien, E., \& Monjok, E., (2014): Assessment of the Knowledge and Utilization of the Partograph among Non-physician Obstetric Care Givers in the University of Calabar Teaching Hospital, Calabar, Nigeria. British Journal of Medicine and Medical Research, 4(36), 57415755.

https://doi.org/10.9734/bjmmr/2014/10853

- Al-dainee, Manar M., Hameed, WafaAdbulKarim, Amean A., Yasir (2015): Effect of the Teaching Program Regarding Partograph on Midwives Knowledge at Delivery Room in KarbalaCityHspitals AlDainee , Kufa Journal for Nursing Sciences, 6(4).

- Allauddin M., Runal Bal, Arunangsu D., Parthajit Mandal, Mayoukh Chakraborty. (2016): Monitoring labour with WHO Modified Partograph- Graphic analysis of labour. American Journal of Obstetrics and Gynecology 68(6):1568-1575.

- Dangel G., (2017): Preventing prolonged labour by using partograph. International journal of Gynecology and Obstetrics 7(1): 8439-1528.

- Fawole A., (2013): "African journal of reproductive health- knowledge and utilization of the partograph among obstetric care givers", vol.12 (1), pp: 22-29.

- Jumaah Z., Neamat, Nasir K., Mohammed, (2016). Effectiveness of Educational Program on Nurses' Knowledge Regarding Partograph in Al-Najaf City. 6(11), 605-615.

- Okusanya B., Ogunjimi O., Osanyin G., Okojie O., \& Oye-Adeniran B., (2018): Effect of training on the knowledge and use of the partograph for low risk pregnancies among health workers in a tertiary hospital in Lagos State, Nigeria. Journal of Community Medicine and Primary Health Care, 30(2), 4754. https://doi.org/10.4314/jcmphc.v30i2

- Kaur, R., (2019): A study to assess the knowledge regarding partograph among staff nurses. International Journal of Pregnancy \& Child Birth, 5(2), 78-81. https://doi.org/10.15406/ipcb.2019.05.00151.

- Lavender, T., Lugina, H., \& Smith, H., (2017): The partograph: A life-saving tool for Africamidwives. Tropical Doctor 37(3):191192.

- Macones, G., Caughey, A., Wood, S., Wrench, I., Huang, J., Norman, M., Pettersson, K., Fawcett, W., Shalabi, M., Metcalfe, A., Gramlich, L., Nelson, G., \& Wilson, R., (2019): Guidelines for postoperative care in cesarean delivery: Enhanced Recovery After Surgery (ERAS) Society recommendations (part 3). American Journal of Obstetrics and Gynecology, 221(3), 247.e1-247.e9. https://doi.org/10.1016 /j.ajog. 2019.04.012.

- Manohari R., (2010): A study to evaluate the effectiveness of self-instructional module on partograph in terms of knowledge among the staff nurses working in selected maternity hospitals at Erode, in partial fulfillment of the requirements for the degree of master of Science in Obstetrics and Gynecological Nursing, Approved by DMIPSR College Research Committee, URI: http://repositorytnmgrmu.ac.in/id/print/5612.

- Mathai M., \& Switzerland, (2015): “clinical Obstetrics and Gynecological -the partograph 
for the prevention of obstructed labour", Vol 52(2), Pp: 256-259

- Nattah, F., Al-Yasir, A., \& Khaleel, M., (2019): Effectiveness of structured teaching program upon midwives' knowledge concerning progress of labor in al-hilla hospitals. Indian Journal of Public Health Research and Development, 10(2), 994-1000. https://doi.org/10.5958/09765506.2019.00426.1

- Pokhrel, H., Kuenzang, Dorji, K., \& Rinzin, D., (2018): Knowledge of Partograph Recording and Interpretation and Its Documentation Status in Samdrup Jongkhar District, Bhutan. International Journal of Innovative Research in Medical Science, 3(12), 2356-2360. https://doi.org/10.23958/ijirms/vol03-i12/503.

- Safe Motherhood Programme Article (2018): partograph in management of labour. Maternal Health and Safe Motherhood Programme. Accessed at www.sciencestage.com.

- Tayade S., \& Jadhao P., (2012): The Impact of Use of Modified WHO Partograph on Maternal and Perinatal Outcome; Dept of Obstetrics and Gynecology, Mahatma Gandhi Institute of Medical Sciences, Sewagram, Wardha, Maharashtra, India. International Journal of Biomedical and Advance Research. 2012;03(04): P256.

- WHO, (2018): Global health observatory. Women and health: Maternal mortality ratio, Accessed at www.apps.who.int on 21/02/2016.

- Yisma, E., Dessalegn, B., Astatkie, A., \& Fesseha, N., (2013): Completion of the modified World Health Organization (WHO) partograph during labour in public health institutions of Addis Ababa, Ethiopia. Reproductive Health, 10(1), 1-7. https://doi.org/10.1186/1742-4755-10-23. 